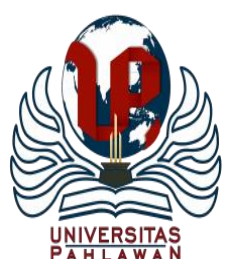

Jurnal Abdidas Volume 2 Nomor 3 Tahun 2021 Halaman 465-471

JURNAL ABDIDAS

http://abdidas.org/index.php/abdidas

\title{
Pelatihan Aplikasi Pembuatan Ujian Online Berbasis Android untuk Guru Sekolah Menengah Pertama
}

\author{
Rahmad Syuhada $^{1 凶}$, Ellanda Purwawijaya ${ }^{2}$, Fahmi Ruziq $^{3}$ \\ Teknologi Informasi, Fakultas Teknologi, Universitas Battuta, Indonesia ${ }^{1,2}$ \\ Informatika, Fakultas Teknologi, Universitas Battuta, Indonesia ${ }^{3}$ \\ E-mail: $\underline{\text { rahmadsyuhada@yahoo.co.id }}{ }^{1}$, ellanda.purwa.wijaya@gmail.com ${ }^{2}$, fahmiruziq89@ gmail.com ${ }^{3}$
}

\begin{abstract}
Abstrak
Pada setiap sekolah, ujian semester merupakan sebuah kegiatan yang wajib dilewati untuk seluruh siswa. Seiring berkembangnya teknologi serta dimasa tatanan kehidupan normal baru membuat setiap sekolah wajib untuk menjalankan kebijakan Pembelajaran Jarak Jauh (PJJ), dengan adanya perangkat Smartphone Android yang siswa miliki serta bantuan paket pembelajaran dari Kementerian Pendidikan dan Kebudayaan, dapat dimanfaatkan untuk kegiatan belajar mengajar dan ujian online. Dalam kegiatan ini, metode yang dilakukan dalam bentuk lokakarya dengan pengajaran langsung melalui aplikasi progam Microsoft Office 365, dalam memudahkan para guru melakukan proses ujian online pada semester pertama masa new normal. Dari hasil pelaksanaan kegiatan ini, muncul minat para guru-guru SMP Negeri 27 Medan untuk menerapkan ujian online berbasis Android di lingkungan sekolah, terlihat dari perwakilan Musyawarah Guru Mata Pelajaran (MGMP) yang sangat antusias dalam mempelajari fitur-fitur yang tersedia, dan pengaturan pengelolaan soal ujian.
\end{abstract}

Kata kunci : digitalisasi, PJJ, Microsoft 365

\begin{abstract}
In every school, the semester exam is an activity that must be passed for all students. The advancement of technology and in the new normal life order makes every school obliged to carry out a Distance Learning (PJJ) policy, with the existence of an Android smartphone device that students have as well as learning package assistance from the Ministry of Education and Culture, which can be used for teaching and learning activities and online examinations. In this activity the method is carried out in the form of a workshop by building directly through the Microsoft Office 365 application, to make it easier for teachers to carry out the online exam process in the first semester of the new normal period. From the results of the implementation of this activity, there was an interest in the teachers of SMP Negeri 27 Medan to implement Android-based online exams in the school environment, it can be seen from the representatives of the Subject Teacher Conference (MGMP) who are very enthusiastic in learning the available features, and managing the management of exam questions.
\end{abstract}

Keywords: digitalization, PJJ, Microsoft 365

Copyright (c) 2021 Rahmad Syuhada, Ellanda Purwawijaya, Fahmi Ruziq

$\triangle$ Corresponding author

Address : Universitas Battuta

Email : rahmadsyuhada@yahoo.co.id

DOI : https://doi.org/10.31004/abdidas.v2i3.298

ISSN 2721- 9224 (Media Cetak)

ISSN 2721- 9216 (Media Online) 
466 Pelatihan Aplikasi Pembuatan Ujian Online Berbasis Android untuk Guru Sekolah Menengah Pertama- Rahmad Syuhada, Ellanda Purwawijaya, Fahmi Ruziq

DOI: https://doi.org/10.31004/abdidas.v2i3.298

\section{PENDAHULUAN}

Kemunculan teknologi dalam menggantikan peran kegiatan sebelumnya yang menggunakan cara-cara tradisional atau belum menggunakan basis data (Limbong,B, 2012). Sebagai contoh sederhana yaitu bagaimana penggunaan internet dapat dirasakan oleh seluruh lapisan masyarakat, khususnya untuk para pelajar dan guru di bidang pendidikan tanpa adanya batasan, baik yang bersifat lokal maupun dalam cakupan yang lebih luas lagi. Hal ini juga sejalan dengan kebijakan pemerintah yang menerapkan salah satu alternatif dengan menciptakan ujian berbasis online yang memanfaatkan akses internet, dimana seluruh siswa tidak lagi menggunakan alat tulis (Kemdikbud, 2020). Berdasarkan surat edaran Mendikbud Nomor 4 Tahun 2020 mengenai Belajar dari Rumah Melalui Pembelajaran Jarak Jauh, terdapat peran penting guru untuk membantu siswa menghadapi ketidakpastian yang disebabkan oleh pandemi, sehingga siswa dituntut untuk terus belajar meskipun kegiatan sekolah normal terganggu.

Dalam kesempatan ini salah satu aspek penghambat dalam kegiatan pembelajaran jarak jauh adalah sedikitnya pemahaman para guru terhadap penggunaan platform pembelajaran. Para guru melakukan ujian daring menggunakan aplikasi pesan singkat atau instant message, dimana soal ujian dibagikan melalui foto atau screenshot, sehingga terlihat kurang menarik dan antusias. Hal tersebut dialami oleh SMP Negeri 27 Medan yang berlokasi di Jalan Pancing Pasar IV No.2, Medan. Dimana harus memfasilitasi siswa agar terlaksananya Ujian Akhir Semester (UAS), namun dikarenakan akses fisik ke sekolah ditutup, sehingga guru harus mengambil keputusan yang cepat untuk memulai dan melaksanakan ujian yang berkelanjutan selama masa pandemi.

SMP Negeri 27 Medan (Gambar 1.1) merupakan UPT yang berada dalam naungan Dinas Pendidikan Kota Medan, Sumatera Utara. Adapun tujuan dari kegiatan Pengabdian Kepada Masyarakat (PKM) ini adalah memberikan pemahaman, pengetahuan dan pelatihan kepada peserta, dalam hal ini adalah guru SMP Negeri 27 Medan tentang teknologi dalam aplikasi pembuatan ujian online berbasiskan Android, mengetahui hal yang perlu dipersiapkan dalam penggunaan aplikasi Microsoft 365 untuk diterapkan dalam metode ujian online berbasis Android,sehingga memperoleh pengetahuan tentang penggunaan aplikasi dalam penyusunan soal ujian online dan pengelolaan nilai hasil ujian. Dengan menggunakan media digital, Prastiti. M (2020) menyatakan bahwa seperti gawai yang dimiliki siswa dapat meminimalkan penggunaan kertas (paperless), siswa-siswi juga dapat mengerjakan soal ujian dari rumah dan tentunya masih dalam pengawasan guru bidang studi masing-masing dengan pengaturan yang telah dibuat. Sehingga nantinya guru dapat berperan aktif dan selalu berinovasi dalam perkembangan teknologi. 
467 Pelatihan Aplikasi Pembuatan Ujian Online Berbasis Android untuk Guru Sekolah Menengah Pertama- Rahmad Syuhada, Ellanda Purwawijaya, Fahmi Ruziq

DOI: https://doi.org/10.31004/abdidas.v2i3.298

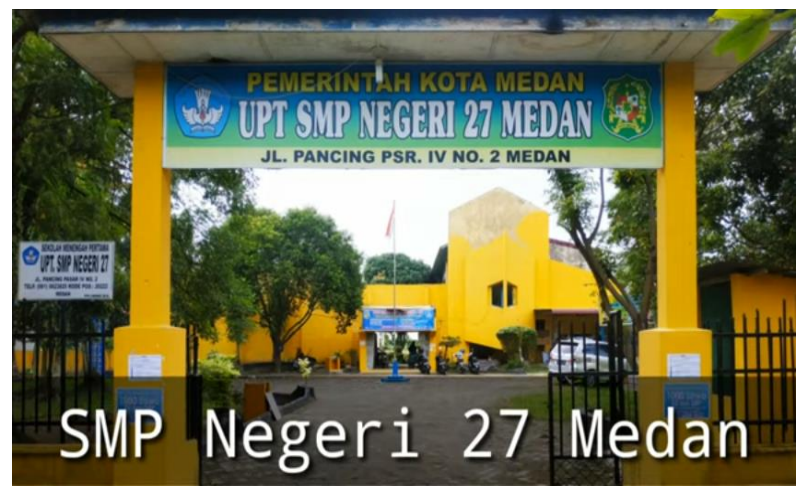

Gambar 1. UPT SMP Negeri 27 Medan

\section{METODE}

Pelaksanaan kegiatan pengabdian masyarakat dilaksanakan pada bulan November 2020. Adapun rangkaian metode penyelesaian dilakukan dengan mengadakan kegiatan pelatihan Microsoft 365, sehingga diharapkan para guru memiliki pengetahuan dan keterampilan dalam menggunakan aplikasi, membuat soal, merancang kurikulum, serta mengolah hasil nilai ujian. Peserta dalam hal ini guru dilatih secara langsung dalam melakukan pengolahan data dan pengaturan soal ujian menggunakan Microsoft 365 di support dengan aplikasi Mobile Exam sebagai aplikasi yang digunakan untuk membantu guru membagi link ujian form agar siswa dapat dengan mudah mengakses ujian. Dalam hal ini dilakukan persiapan sebagai berikut :

a. Membentuk kegiatan yang akan dilakukan secara langsung penggunaan aplikasi untuk pembuatan soal ujian online berbasis Android, dimana peserta pelatihan terdiri dari 9 kelompok Guru MGMP (Musyawarah Guru Mata Pelajaran).

b. Setiap kelompoknya terdiri dari 3 orang, dipantau langsung oleh seorang koordinator (Tim Pelaksana). Ketua pelaksana memberikan arahan dan pedoman kepada seluruh peserta pelatihan untuk menjelaskan, memperlihatkan, mempertunjukkan, serta memvisualisasikan dalam bentuk paparan dan langkah-langkah untuk membuat soal ujian berbasis Android di depan seluruh peserta pelatihan.

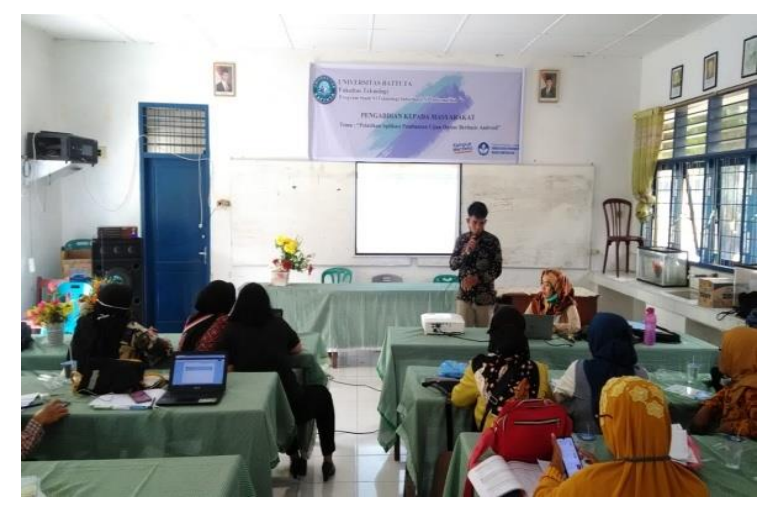

Gambar 2. Pelatihan Aplikasi Pembuatan Soal Ujian Online Berbasis Android

c. Peserta pelatihan dibekali perangkat laptop dan gawai untuk penggunaan aplikasi ujian online, agar dapat mempraktikkannya langsung, sehingga memahami proses pengaturan dan pembuatan soal pada saat pelaksanaan ujian online di kemudian hari, sesuai dengan yang diinginkan dalam capaian pembelajaran.

d. Menentukan persiapan alat dan bahan untuk simulasi serta menentukan waktu pelaksanaan dan durasi kegiatan pengabdian bersama tim pelaksana. 


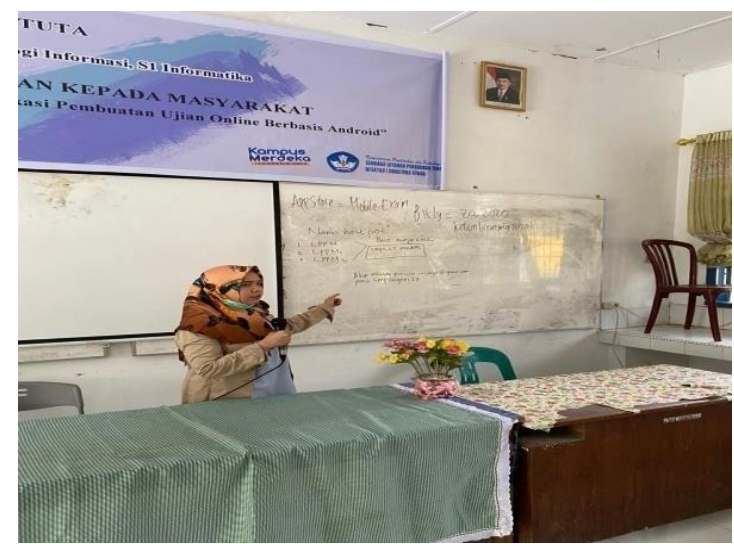

Gambar 3. Penjelasan Durasi Pembuatan Soal Ujian Online Berbasis Android

\section{e. Relevansi Bagi Guru}

Kegiatan ini memiliki nilai dan manfaat dengan kebutuhan guru dimasa era normal baru dengan sistem Pembelajaran Jarak Jauh (PJJ). Berdasarkan hasil survei sebelum pelaksanaan, masih banyak guru-guru yang kesulitan dengan metode ujian apa yang harus dilakukan dengan efektif pada masa pembelajaran dari rumah ini. Sehingga dengan adanya pelatihan ini, diharapkan guru-guru dapat menerapkan ujian online berbasis Android tersebut dengan menggunakan aplikasi Microsoft 365 dalam proses pembuatan soal.

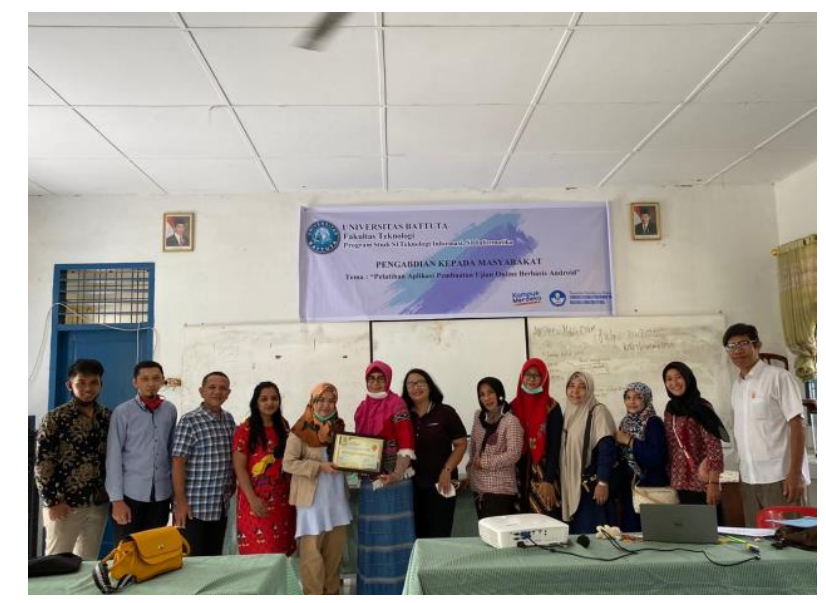

Gambar 4. Foto bersama Tim Pelaksana Pengabdian Masyarakat dengan Mitra

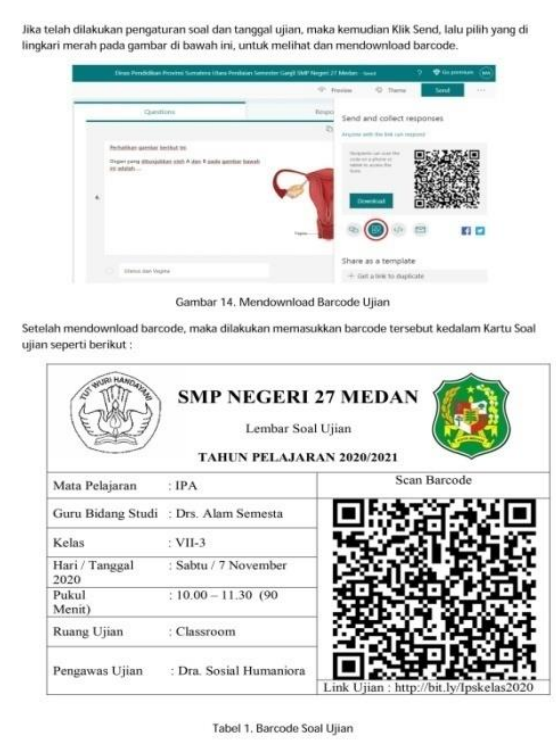

Gambar 5. Pembuatan Soal dan Barcode

\section{HASIL DAN PEMBAHASAN}

Kegiatan pengabdian masyarakat ini memberikan dampak yang sangat positif bagi guru SMP Negeri 27 Medan dengan menambah wawasan dan keahlian dalam memanfaatkan platform media pembelajaran. Para guru dapat membuat soal ujian online yang menarik sehingga terkesan lebih variatif dan siswa juga antusias dalam menjawab soal. Berdasarkan hasil dari wawancara terhadap para peserta kegiatan, kami dari pihak tim pelaksana mengambil kesimpulan mengenai tercapainya tujuan dari kegiatan Pengabdian Kepada Masyarakat (PKM) ini adalah semata-mata untuk memberikan pengetahuan dan pelatihan tentang teknologi dalam aplikasi pembuatan ujian online berbasiskan Android. Dari hasil kegiatan yang dilakukan melalui pelatihan, sesuai dengan harapan kami munculnya minat para guru-guru SMP Negeri 27 Medan untuk menerapkan ujian online berbasis android 
dilingkungan sekolah, terlihat dari antusiasnya perwakilan Musyawarah Guru Mata Pelajaran (MGMP) dalam mempelajari fitur-fitur yang tersedia, dan pengaturan pengelolaan soal serta hasil ujian pada aplikasi. Terdapat beberapa guru mengalami kesulitan dalam mengatur pemilihan urutan soal dan optional, namun setelah diberikan pemahaman oleh sesama rekan guru yang lain, kesulitan itu perlahan mulai dirasa biasa saja, bahkan pada simulasi terakhir telah mahir menggunakan aplikasi dalam membuat soal ujian dan melihat nilai hasil ujian dari simulasi yang dilakukan antara guru dan murid sebagai percontohan. Mengenai penjelasan proses alur flow penggunaan aplikasi ujian, maka alur penggunaan aplikasi dapat terlihat pada tabel dibawah ini :

\begin{tabular}{|c|c|}
\hline & • Menyusun soal ujian di Microsoft 365 \\
\hline & -Melakukan pengaturan di menu setting \\
\hline & - Mendownload QR code form ujian \\
\hline & - Membacakan panduan ujian untuk siswa \\
\hline & $\begin{array}{l}\text { - Membagikan QR code kepada seluruh peserta } \\
\text { ujian }\end{array}$ \\
\hline
\end{tabular}

Diagram 1. Penggunaan Aplikasi untuk Guru

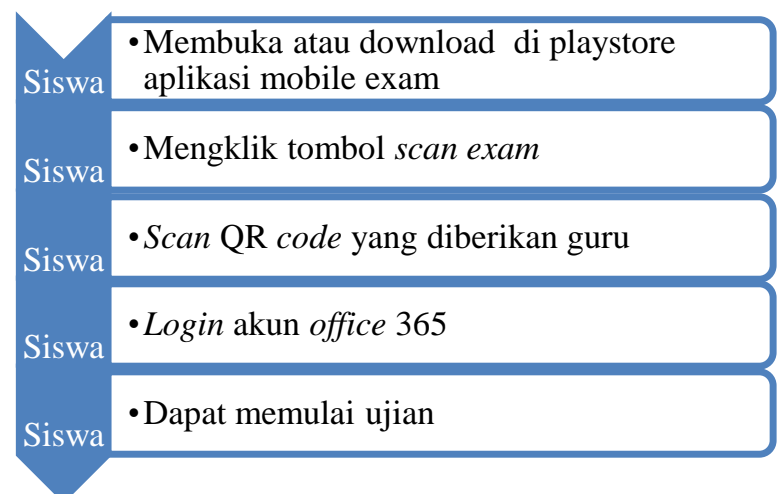

Diagram 2. Penggunaan Aplikasi untuk Siswa

Kegiatan ini memiliki nilai dan manfaat dengan kebutuhan guru di masa era normal baru dengan sistem Pembelajaran Jarak Jauh (PJJ). Berdasarkan hasil survei sebelum pelaksanaan masih banyak guru-guru yang kesulitan dengan metode ujian apa yang harus dilakukan dengan efektif pada masa pembelajaran dari rumah ini. Sehingga dengan adanya pelatihan ini, diharapkan guru-guru dapat menerapkan ujian online berbasis Android tersebut dengan menggunakan aplikasi Microsoft 365. Setelah selesai dilakukan kegiatan, peserta pelatihan dalam hal ini guru SMP Negeri 27 Medan mengalami peningkatan pengetahuan dan pemahaman dalam menggunakan aplikasi program Microsoft 365 sebagai form pembuatan soal, terlihat dari monitoring evaluasi hasil kegiatan pada tabel dibawah ini.

Tabel 1. Pengetahuan Guru Sebelum Kegiatan

\begin{tabular}{|c|c|c|c|c|c|c|}
\hline \multirow{2}{*}{ No. } & \multirow{2}{*}{ Indikator } & \multicolumn{5}{|c|}{ Responden / Skor } \\
\hline & & 1 & 2 & 3 & 4 & 5 \\
\hline 1 & $\begin{array}{lcllll}\text { Keterampilan guru dalam memecahkan masalah pembuatan } & \text { soal ujian } \\
\text { menggunakan } & \text { Microsoft } 365\end{array}$ & 3 & 3 & 4 & 3 & 3 \\
\hline 2 & $\begin{array}{l}\text { Kemampuan guru dalam mengarahkan dan menggerakkan rekan sejawat untuk } \\
\text { mengikuti pelatihan pembuatan soal ujian berbasis Android }\end{array}$ & 4 & 3 & 3 & 3 & 3 \\
\hline 3 & $\begin{array}{l}\text { Kemampuan guru dalam melakukan evaluasi dan perbaikan aplikasi serta } \\
\text { kegiatan kerjasama dengan siswa (narasumber) dalam pelatihan pembuatan soal }\end{array}$ & 3 & 4 & 3 & 4 & 3 \\
\hline 4 & Keterampilan guru menggunakan tools program aplikasi Microsoft 365 & 4 & 3 & 3 & 3 & 3 \\
\hline 5 & Kemampuan guru untuk menerapkap ujian online melalui siswa & 3 & 3 & 3 & 3 & 3 \\
\hline & Jumlah Skor & 17 & 16 & 16 & 16 & 15 \\
\hline & Nilai & 85 & 80 & 80 & 80 & 75 \\
\hline & Rata-rata Nilai & & & 80 & & \\
\hline
\end{tabular}


470 Pelatihan Aplikasi Pembuatan Ujian Online Berbasis Android untuk Guru Sekolah Menengah Pertama- Rahmad Syuhada, Ellanda Purwawijaya, Fahmi Ruziq

DOI: https://doi.org/10.31004/abdidas.v2i3.298

Tabel 2. Pengetahuan Guru Setelah Kegiatan

\begin{tabular}{|c|c|c|c|c|c|c|}
\hline \multirow{2}{*}{ No. } & \multirow{2}{*}{ Indikator } & \multicolumn{5}{|c|}{ Responden / Skor } \\
\hline & & 1 & 2 & 3 & 4 & 5 \\
\hline 1 & $\begin{array}{l}\text { Keterampilan guru dalam memecahkan masalah pembuatan soal ujian } \\
\text { menggunakan }\end{array}$ & 4 & 4 & 4 & 4 & 3 \\
\hline 2 & $\begin{array}{l}\text { Kemampuan guru dalam mengarahkan dan menggerakkan rekan sejawat untuk } \\
\text { mengikuti pelatihan pembuatan soal ujian berbasis Android }\end{array}$ & 4 & 4 & 3 & 4 & 4 \\
\hline 3 & $\begin{array}{l}\text { Kemampuan guru dalam melakukan evaluasi dan perbaikan aplikasi serta } \\
\text { kegiatan kerjasama dengan siswa (narasumber) dalam pelatihan pembuatan soal }\end{array}$ & 4 & 4 & 3 & 4 & 4 \\
\hline 4 & Keterampilan guru menggunakan tools program aplikasi Microsoft 365 & 4 & 4 & 3 & 4 & 3 \\
\hline 5 & Kemampuan guru untuk menerapkap ujian online melalui siswa & 4 & 4 & 3 & 4 & 4 \\
\hline & Jumlah Skor & 20 & 20 & 16 & 20 & 18 \\
\hline & Nilai & 100 & 100 & 80 & 100 & 90 \\
\hline & Rata-rata Nilai & & & 94 & & \\
\hline
\end{tabular}

Pada tabel diatas, terlihat perbedaan ratarata nilai sebelum dan setelah dilakukan proses pelatihan pembuatan soal. Dengan meningkatnya keterampilan guru-guru dalam membuat dan mengatur soal ujian dapat membantu memudahkan ujian online di masa era normal baru kepada siswa.

\section{SIMPULAN}

Berdasarkan pengamatan hasil kegiatan dapat ditarik beberapa kesimpulan sebagai berikut yakni: setelah dilakukan pelatihan timbul minat para guru-guru SMP Negeri 27 Medan untuk menerapkan ujian online berbasis Android (Android Online Test) di lingkungan sekolah. Meningkatnya motivasi perwakilan Musyawarah Guru Mata Pelajaran (MGMP) untuk mempelajari fitur-fitur yang tersedia, dan pengaturan pengelolaan soal serta hasil ujian pada aplikasi Microsoft 365. Beberapa guru telah mahir menggunakan aplikasi untuk membuat soal ujian dan melihat nilai hasil ujian.

\section{Saran}

Mengingat besarnya manfaat kegiatan pengabdian masyarakat ini, maka untuk selanjutnya perlu tindak lanjut berupa :
1. Para peserta dalam hal ini Guru-guru SMP Negeri 27 Medan dapat mempraktikkan ilmu yang diperoleh dalam ujian semester ganjil tahun ajaran 2020/2021 di masa era normal baru dalam Pembelajaran Jarak Jauh (PJJ).

2. Dukungan pihak sekolah dalam hal ini kepala sekolah SMP Negeri 27 Medan untuk mendukung sarana dan prasarana dalam hal peningkatan kualitas sumber daya manusia dalam hal ini guru SMP Negeri 27 Medan di bidang IT.

\section{UCAPAN TERIMAKASIH}

Pengabdian kepada masyarakat ini merupakan salah satu bentuk perwujudan Tri Dharma Perguruan Tinggi yang dilaksanakan oleh civitas akademika Fakultas Teknologi Program Studi Teknologi Informasi, Universitas Battuta. Materi ini dipilih berdasarkan kebutuhan guruguru di sekolah, terutama dalam pelaksanaan ujian dimana kondisi terakhir dimasa era normal baru diharuskannya Pembelajaran Jarak Jauh (PJJ). Materi lokakarya ini mencakup pembuatan soal 
471 Pelatihan Aplikasi Pembuatan Ujian Online Berbasis Android untuk Guru Sekolah Menengah Pertama- Rahmad Syuhada, Ellanda Purwawijaya, Fahmi Ruziq

DOI: https://doi.org/10.31004/abdidas.v2i3.298

menggunakan aplikasi dan pengelolaan nilai menggunakan Microsoft 365.

Dalam kesempatan ini, kami mengucapkan terima kasih yang sebesar-besarnya kepada :

1. Ketua Lembaga Penelitian dan Pengabdian Masyarakat Universitas Battuta yang telah memberikan kemudahan dalam pelaksanaan pengabdian.

2. Dekan Fakultas Teknologi Universitas Battuta yang telah memberikan fasilitas dalam kegiatan pengabdian ini.

3. Ketua Program Studi Teknologi Informasi yang telah memberikan dukungan dalam pelaksanaan kegiatan pengabdian ini.

4. Staf dosen dan pegawai administrasi Universitas Battuta yang telah membantu kelancaran pelaksanaan kegiatan pengabdian ini.

5. Koordinator, Kepala Sekolah, PKS Kurikulum, Staf Pegawai dan seluruh Guru SMP Negeri 27 Medan yang telah turut berpartisipasi aktif dalam pelaksanaan kegiatan pengabdian ini.

Akhir kata kami selaku tim pelaksana kegiatan pengabdian masyarakat mengucapkan terima kasih.

\section{DAFTAR PUSTAKA}

Kemdikbud.(2020).Panduan Pembelajaran Jarak Jauh Belajar Dirumah Masa Covid-19. Jakata:PUSDATIN Kementerian Pendidikan dan Kebudayaan

Limbong,B.(2012).Peran Teknologi Informasi Dalam Pengembangan Vokasi Pendidikan Tinggi. Jurnal Pendidikan Indonesia(JPI), 1-8

Prastiti,M.(2020, September 18).Media Pembelajaran Berteknologi Digital. Diakses dari:

http://pena.belajar.kemdikbud.go.id/2020/09/ media-pembelajaran-berteknologi-digital/

Roy, S. (2019, Desember 2).Ujian Sekolah Hanya Dari HP Android dengan Aplikasi Mobile Exam. Diakses dari: https://www.androidponsel.com/6776/aplikas i-mobile-exam/

Sarana Solusindo (2018, Agustus 15). 5 Fitur Unggulan Yang Ada Di Office 365. Diakses dari: https://www.solusi.com/5-fitur-unggul/ 